\title{
The Analysis of Pingyao Ancient Town Street Spaces and View Spots Reachability by Space Syntax
}

\section{Dengfei Li, Xianchun Yan*, Yan Yu}

Key Laboratory of Southwest China Wildlife Resources Conservation, China West Normal University, Ministry of Education, Nanchong, China

Email:18780735598@163.com, *965911029@qq.com,315222742@qq.com

How to cite this paper: Li, D.F., Yan, X.C., and Yu, Y. (2016) The Analysis of Pingyao Ancient Town Street Spaces and View Spots Reachability by Space Syntax. Journal of Data Analysis and Information Processing, 4, 177186.

http://dx.doi.org/10.4236/jdaip.2016.44015

Received: October 31, 2016

Accepted: November 21, 2016

Published: November 24, 2016

Copyright (c) 2016 by authors and Scientific Research Publishing Inc. This work is licensed under the Creative Commons Attribution International License (CC BY 4.0).

http://creativecommons.org/licenses/by/4.0/

\begin{abstract}
The Pingyao ancient town is one of the four largest ancient cities in China. This study analyzes street spaces characteristic and view spots reachability of the Pingyao ancient town using space syntax. Then, it is concluded that the integration and reachability of street spaces are relatively higher in the northern ancient town; the accessibility among street spaces is relatively higher in the northeastern ancient town; and most of the ancient town street spaces are very open. Furthermore, the reachability of 14 view spots and their 4 corresponding street spaces is relatively higher in the 20 view spots and their 9 corresponding street spaces. Finally, some suggestions are presented to the tourism development of Pingyao ancient town based on the above conclusions.
\end{abstract}

\section{Keywords}

Pingyao Ancient Town, Space Syntax, Reachability, Street Space

\section{Introduction}

The Pingyao ancient town is located in the Pingyao county of Shanxi province in China, and it was built in the Zhou Dynasty (827BC-782BC). It has a long history, and it is preserved perfectly, and it is one of the four largest ancient cities in China. In addition, it is also one of the two ancient towns declaring the cultural heritage of world with the whole ancient town successfully in China. To date, the studies on Pingyao ancient town are mainly focused on cultural protection and tourism development [1] [2] [3] [4]. So the study on its street spaces is scarce [5].

Space syntax was invented by Bill Hillier and Julienne Hanson in the late 1970s [6]. 
Afterwards, studies on space syntax are increasing, and space syntax is generally used in the fields of architecture and urban space [7] [8] [9] [10]. However, the studies on ancient town by space syntax are relatively less so far [11] [12] [13]. Therefore, this paper analyzes the characteristic of street spaces and the reachability of view spots for Pingyao ancient town using the special method: space syntax, and it is aimed at enriching the research contents of Pingyao ancient town, and it could provide academic basis and directive function for the development of tourism activity in Pingyao ancient town.

\section{Materials and Methods}

Space syntax is a method of studying space structure by quantified descriptions of residential space structure of buildings, settlements, cities and landscape [14]. The basic principle of space syntax is space division. According to the space situations of geographic objects, there are 3 basic approaches: the axial method, the convex polygon method and the dividing view area method. Generally, the axial method is applied to the serried buildings in the urban system, while the convex polygon method or the dividing view area method is applied to the nonlinear spaces [15].

In the study of Pingyao ancient town street spaces, considering the layout of them, the axial method is used to divide street spaces. Meanwhile, the syntax analysis software of Axwoman 3.0-system extension module of Arcview 3.3 is used to acquire axial map of street spaces. The axial map shows the expression and description of space structure of intersecting axial lines over whole spaces [14]. In addition, the variables of space syntax are as follows: connectivity value, control value, depth value and integration value, and their formulas are all showed in the Table 1 [16].

We acquire the plan of Pingyao ancient town street spaces and view spots (Figure 1) by electronic traffic map of China (http://www.521yy.com/tools/map/), and analyze the connectivity degree, the control degree, the total depth degree and the integration degree of street spaces by syntax analysis software.

Table 1. The variables of space syntax.

\begin{tabular}{|c|c|}
\hline Variable Name & Formula \\
\hline Connectivity Value $\left(C_{i}\right)$ & $\begin{array}{l}C_{i}=k \text {, } C_{i} \text { denotes the connectivity value of the } i \text { space, } k \text { is the space } \\
\text { number of directly connected spaces with the } i \text { space. }\end{array}$ \\
\hline Control Value $\left(C t r{ }_{i}\right)$ & $\begin{array}{l}C t r l_{i}=\sum_{j=1}^{k} \frac{1}{C_{j}} ; k \text { is the space number of directly connected spaces with the } \\
i \text { space, } C_{j} \text { denotes the connectivity value of the } j \text { space. }\end{array}$ \\
\hline Depth Value $\left(M D_{i}\right)$ & $\begin{array}{l}M D_{i}=\sum_{j=1}^{n} d_{i j} /(n-1) \quad(j \neq i) ; d_{i j} \text { denotes the shortest distance of any two } \\
\text { points: } i \text { and } j, \sum_{j=1}^{n} d_{i j} \text { is the total depth value, } n \text { is the sum of points. }\end{array}$ \\
\hline Integration Value $\left(R A_{i}\right)$ & $\begin{array}{l}R A_{t}=\frac{2\left(M D_{i}-1\right)}{(n-2)} ; M D_{i} \text { is the mean depth value, } d_{i j} \text { denotes the shortest } \\
\text { distance of any two points: } i \text { and } j, n \text { is the sum of points. }\end{array}$ \\
\hline
\end{tabular}


(1) Huiwulin Museum

(2) Guild Hull of Chinese Commerce

(3) Rishengchang Exchange Shop

(4) Weitaihou Exchange Shop

(5) Guminju expo garden

(6) First Escort Agency of North China

(7) Qingxuguan

(8) Tianjixiang Museum

(9) Weishengchang Exchange Shop

(10) Mingqing Ancient Street

(11) Xietongqing Exchange Shop

(12) Escort Agency of China

(13) Escort Agency of Tongxinggong

(14) Baichuantong Exchange Shop

(15) Xianya Museum

(16) Temple of Chenghuang

(17) Temple of Caishen

(18) Temple of Wen

(19) Miaoshimincangbao Museum

(20) Leilvtai's Former Residence

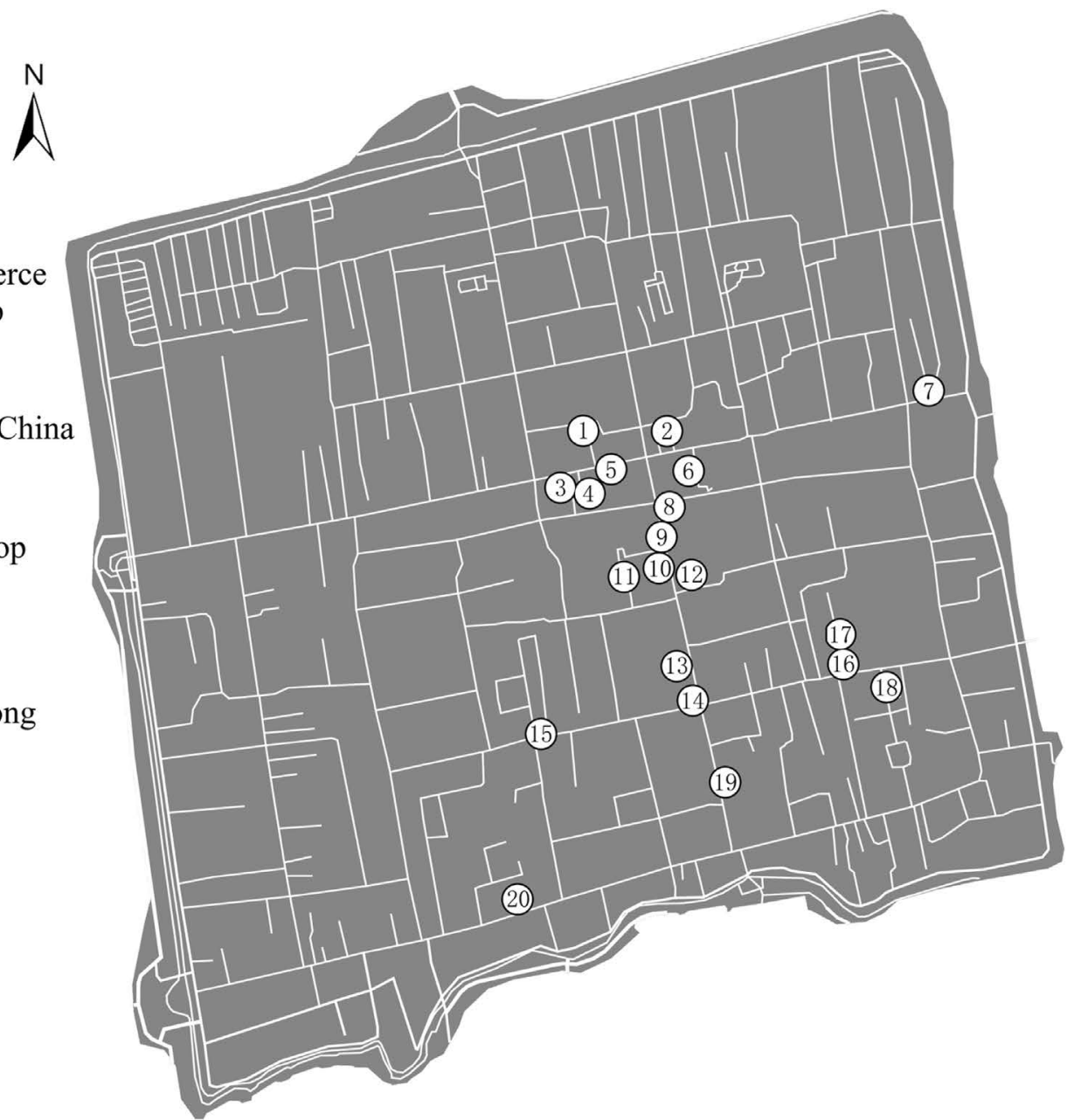

Figure 1. The plan of Pingyao ancient town street spaces and view spots.

\section{Results and Analysis}

\subsection{Analysis of Street Space Characteristic}

1) The connectivity degree reflects the permeability of street spaces. As shown in Figure 2, the higher the value of line, the better the permeability of street space. The street spaces have higher connectivity degree, and also have stronger vision reachability, and they have more relevance with surrounding spaces. The Figure 2 also shows that the connectivity degree of northern street spaces is relatively higher, but the connectivity degree of southern street spaces is universally lower. Only 3 street spaces have relatively higher connectivity degree in the south of ancient town.

2) The control degree reflects one space controls adjacent spaces. As shown in Figure 3 , the higher the value of line, the stronger the control of street spaces. The street spaces have higher control degree, and also have higher reachability. The Figure 3 also shows that the control degree of northern street spaces is relatively higher, but the control degree of southern street spaces is universally lower. Only 4 street spaces have relatively higher control degree in the southern ancient town. 


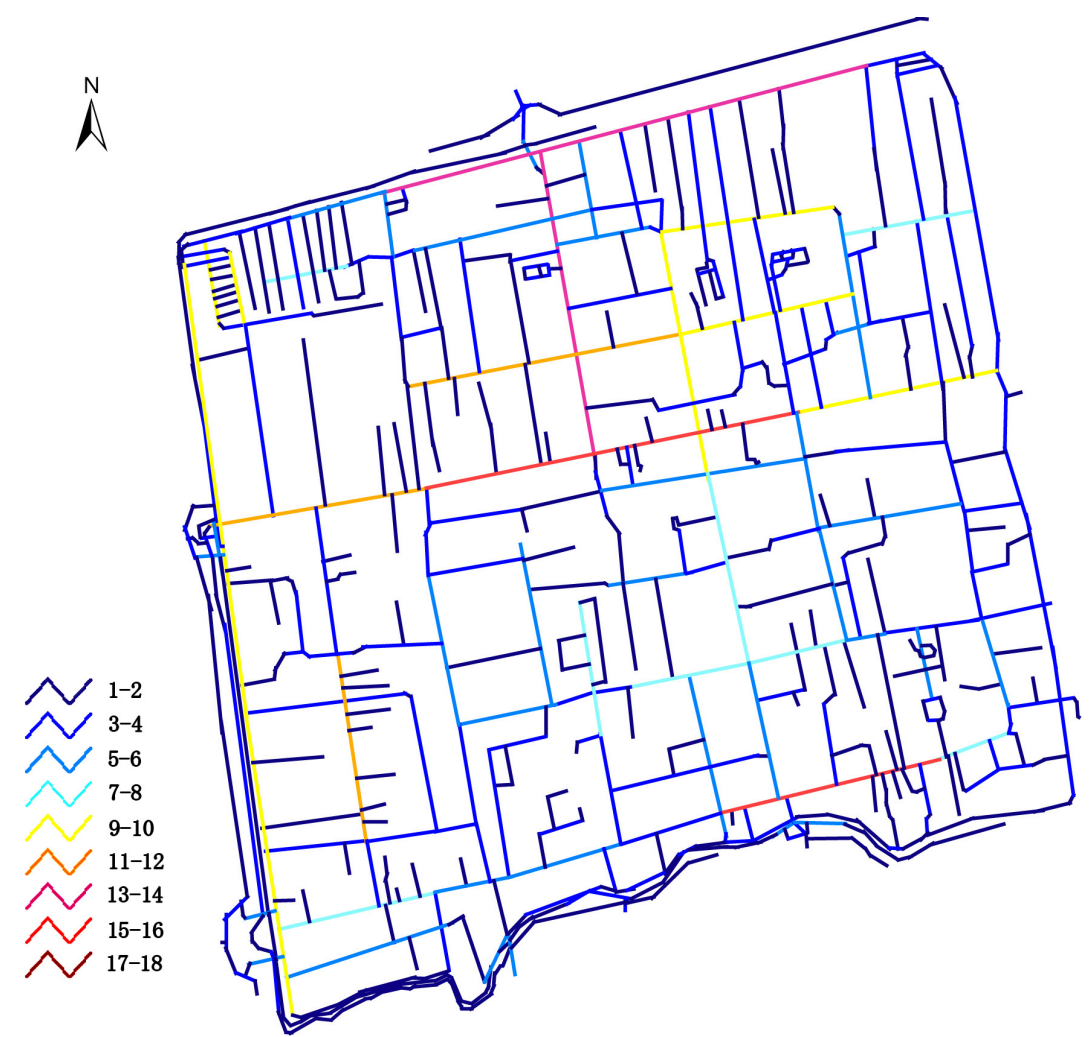

Figure 2. The space syntax graph of connectivity degree.

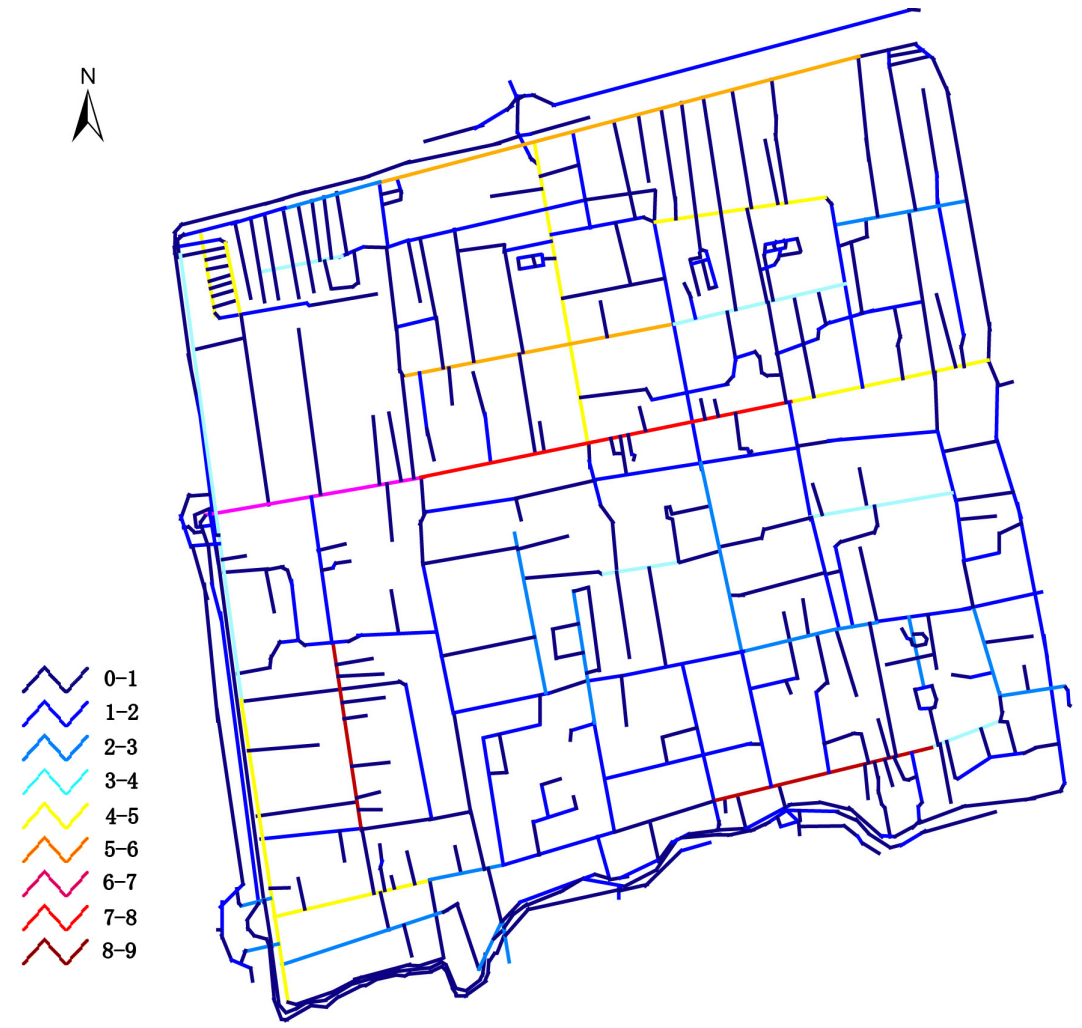

Figure 3. The space syntax graph of control degree. 
3) The total depth degree reflects the openness of street spaces. As shown in Figure 4 , the value of line is lower, then its reachable steps are less, and the street space is more open. Furthermore, the Figure 4 shows the total depth degree is universally low in whole ancient town, therefore it is proved that the openness of most of street spaces is high in the ancient town.

4) The integration degree reflects the congregate degree or discrete degree of one space with other spaces, and it also reflects the reachability and accessibility of street spaces. Integration degree consists of the local integration degree and the total integration degree. The local integration degree exposes the relationship between one space and its adjacent spaces. As shown in Figure 5, the higher the value of line, the higher the local integration degree. The street space has higher value, so it also has higher accessibility degree with adjacent spaces, and it could attract a large number of people. The Figure 5 also shows that the local integration degree of street spaces is relatively higher in the central area of ancient town, and it exposes that the accessibility degree of street spaces is higher in the central area. Total Integration degree exposes the relationship between one space and all other spaces in the ancient town. As shown in Figure 6, the higher the value of line, the higher the total integration degree. The street

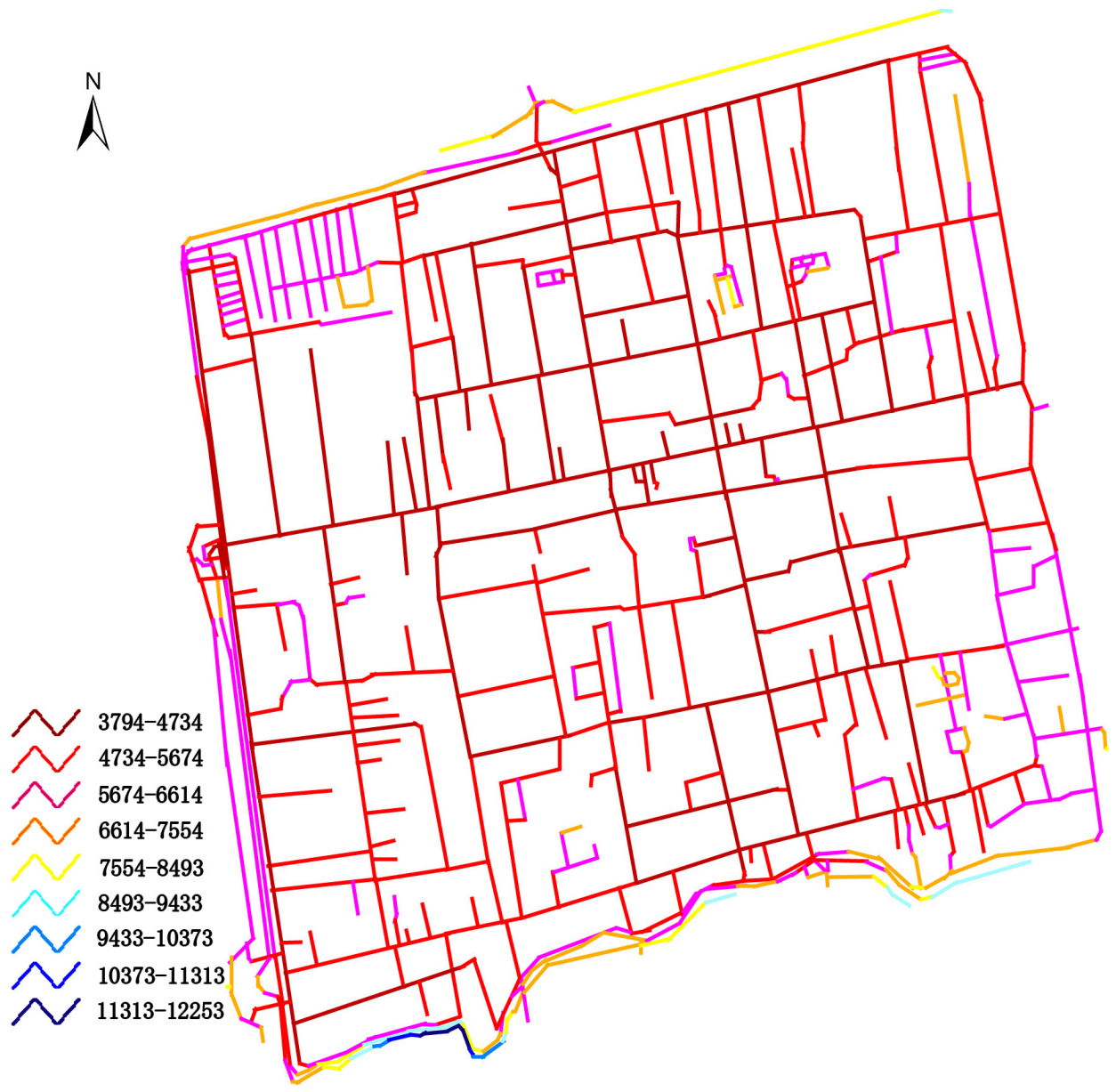

Figure 4. The space syntax graph of total depth degree. 


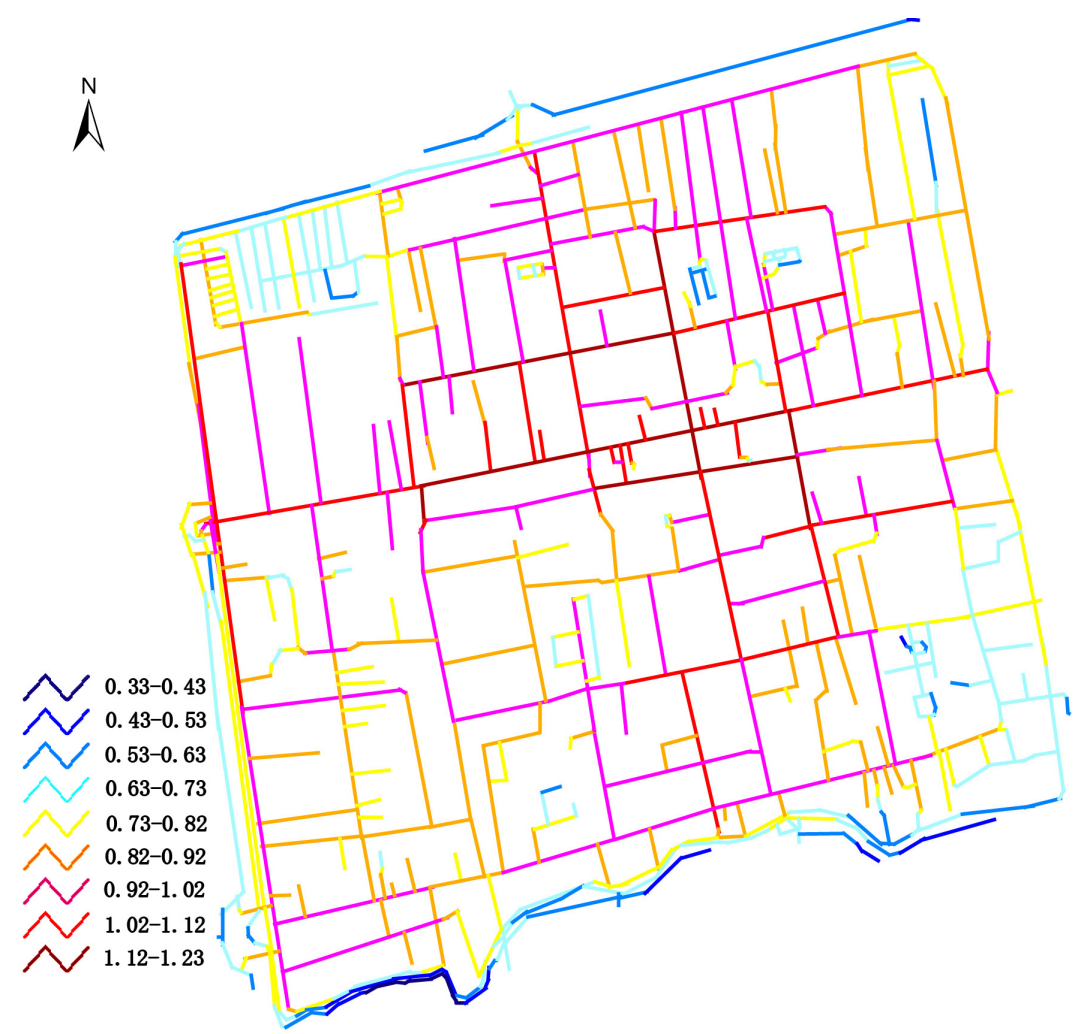

Figure 5. The space syntax graph of local integration degree.

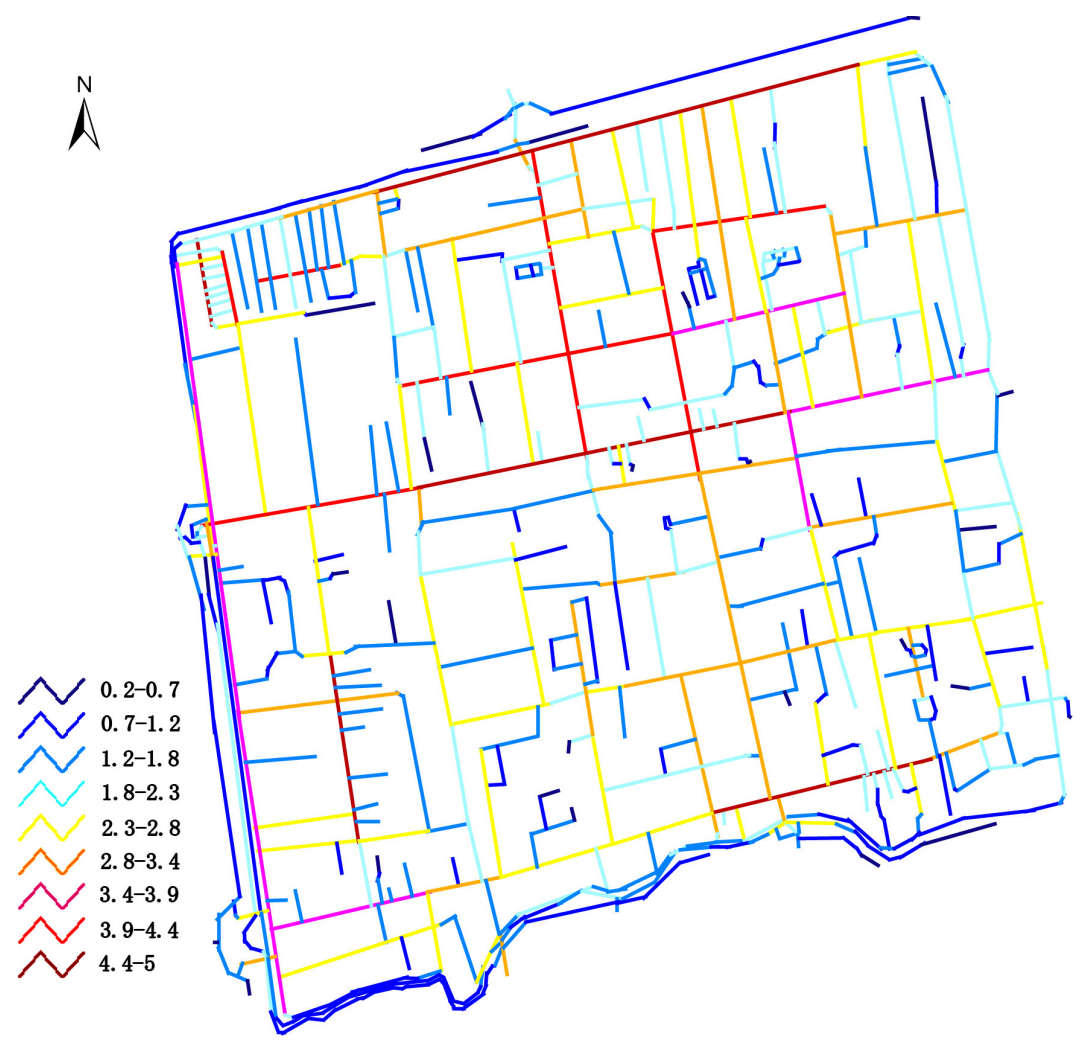

Figure 6. The space syntax graph of total integration degree. 
space has higher total integration degree, then the accessibility degree and congregate degree of it are also higher in the whole ancient town. The Figure 6 also shows that the total integration degree of street spaces is relatively higher in the northern ancient town, especially in the northeastern area of ancient town, and they also have higher congregate degree in the whole ancient town.

\subsection{Analysis of Quantized Data of View Spots Reachability}

After analyzing the quantized data of axial map by software of Axwoman 3.0, we acquire Figure 7 and Figure 8 (Figure 7 shows the connectivity value, the control value, the local integration value and the total integration value of 9 street spaces, Figure 8 shows the total depth value of 9 street spaces). Actually, there are 591 axial lines replace the whole street spaces, but we only list 20 view spots and 9 corresponding street spaces (Table 2), and analyze their data contrastively. Initially, as shown in Figure 7 and Figure 8 , the connectivity value, the control value and the integration value of eastern Xida street and western Dongda street are the highest in all listed street spaces, and its total depth value is relatively higher. Therefore, it means that the 5 corresponding view spots of Xida street and western Dongda street have relatively higher reachability, then it is

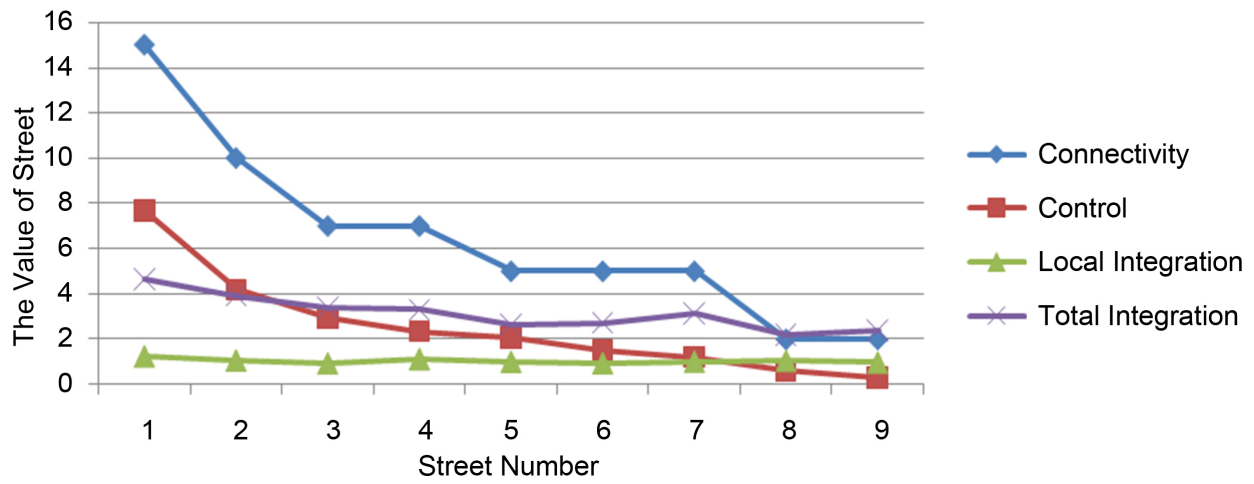

Figure 7. The value of street.

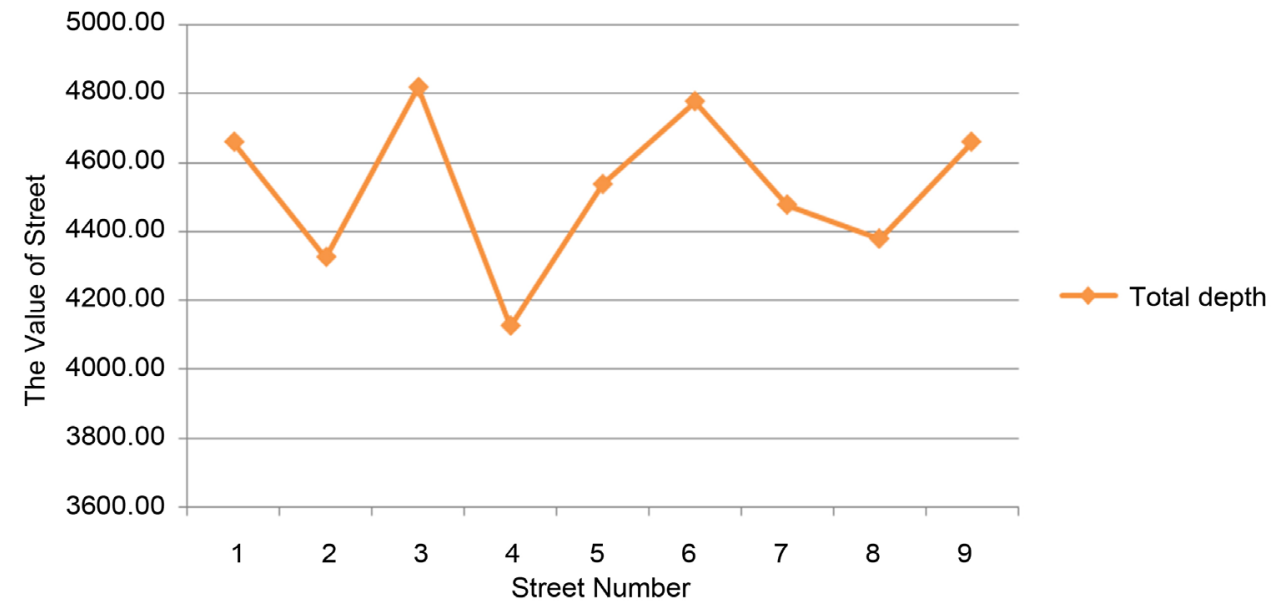

Figure 8. The value of street. 
Table 2. The view spots and corresponding streets.

\begin{tabular}{|c|c|c|}
\hline Street Number & Street Name & View Spots Name \\
\hline 1 & $\begin{array}{l}\text { Eastern Xida Street and } \\
\text { Western Dongda Street }\end{array}$ & $\begin{array}{c}\text { Huiwulin Museum, Guild Hull of Chinese } \\
\text { Commerce, Rishengchang Exchange Shop, } \\
\text { Weitaihou Exchange Shop, } \\
\text { Guminju expo garden }\end{array}$ \\
\hline 2 & Eastern Dongda Street & Qingxuguan \\
\hline 3 & Zhengfu Street & Xianya Museum \\
\hline 4 & Mingqing Street & $\begin{array}{l}\text { Tianjixiang Museum, Weishengchang } \\
\text { Exchange Shop, Mingqing Ancient Street, } \\
\text { Xietongqing Exchange Shop, } \\
\text { Escort Agency of China, Escort Agency of } \\
\text { Tongxinggong, Baichuantong Exchange Shop }\end{array}$ \\
\hline 5 & $\begin{array}{c}\text { Western Chenghuang Temple } \\
\text { Street }\end{array}$ & Temple of Chenghuang, Temple of Caishen \\
\hline 6 & Shangximen Street & Leilvtai's Former Residence \\
\hline 7 & Nanda Street & Miaoshimincangbao Museum \\
\hline 8 & Southern Road of Dongda Street & First Escort Agency of North China \\
\hline 9 & $\begin{array}{c}\text { Eastern Chenghuang Temple } \\
\text { Street }\end{array}$ & Wen Miao \\
\hline
\end{tabular}

easy for tourists to discover these view spots, but the reachable steps are too many. Moreover, the integration, the control and the accessibility of Mingqing street are relatively lower, and its total depth value is the lowest, so it means that the reachability of 7 corresponding view spots is also relatively lower, but the reachable steps are the least. Finally, the connectivity value, the control value and the integration value of Eastern Dongda Street are relatively higher, but its depth value is relatively lower. Therefore, after comprehensive consideration of all value, the corresponding view spot of eastern Dongda street has relatively higher reachability, then the integration, the control, the accessibility and the openness of it are also relatively higher.

\section{Conclusions and Discussions}

The space structure is something that is difficult to be described, and its function is also difficult to be perceived, so it is usually ignored or forgotten. However, the merit of space syntax is the fact that it could show space structure explicitly on the graph by computational analysis. Through analysis of the street spaces characteristic and view spots reachability of Pingyao ancient town by space syntax, we come to conclusions as follows: most of the Pingyao ancient town street spaces are very open; the integration and the control of northern street spaces are relatively higher; and the accessibility of northeastern street spaces is relatively higher in the ancient town. Additionally, through contrastive analysis of quantized data of 20 view spots and 9 corresponding street spaces, we come to the conclusion that the reachability of 14 corresponding view spots of eastern Xida street and western Dongda street, eastern Dongda street, Zhengfu street and Mingqing street is relatively higher. On the contrary, the reachability of the other 6 
view spots and 5 corresponding street spaces is relatively lower. Finally, we offer some suggestions for the tourism development of Pingyao ancient town based on the above conclusions, and the details are as follows:

1) In the future planning and development of ancient town, the connectivity of southwestern street spaces should be increased to improve the reachability of them. For example, it could increase the connectivity degree of street spaces by increasing the connection between one street and its neighboring streets or establishing passageways across the dumped buildings to connect with the surrounding streets. Thus, the permeability and reachability of southwestern street spaces would be better.

2) Some streets have relatively higher integration degree, such as Xida street, Dongda street and Mingqing street, and they connect with various view spots. These streets should be broadened to accommodate more tourists, because the traffic would be terrible during the peak tourist time. With the continuous development of tourism, broadening streets are also beneficial for the sustainable development of ancient town.

3) Many of northwestern street spaces have relatively higher connectivity degree and integration degree, and they would gather a large number of people. Therefore, it is suitable for developing commercial and tourist activities in those streets to exert the integrated function of them, and it would promote the development of economy.

It should be noted that this study has been analyzed only by space syntax, and we have to point out that we do not visit in the Pingyao ancient town street spaces. Therefore, the analysis of street spaces is about the planar spaces rather than the three-dimensional spaces data. So the study on Pingyao ancient town needs to be more profound and more abundant in future.

\section{Acknowledgements}

The research is financed by the Sichuan Research Center for Landscape and Recreation Research Project (JGYQ201407) and the China West Normal University Innovation Team of Regional Tourism Development Research Project (CXTD2013-14).

\section{References}

[1] Tao, W., Jiang, W. and He, X. (2014) The Morphological Change of Vernacular Dwelling Gate and Conceptual Representation of Home: A Case Study of Pingyao. Geographical Research, 12, 2418-2426.

[2] Feng, W.H. and Shao, X.Y. (2015) The Preliminary Study on The Business Network of Tourism Cluster: A Case of Pingyao Ancient City. Human Geography, 5, 134-139+146.

[3] Zhou, B., Song, S. and Huang, W.Q. (2012) Evaluation of Cultural Heritage Tourism Development Based on Entropy Technology and AHPA Case of Pingyao Ancient City, Shanxi Province. Journal of Arid Land Resources and Environment, 9, 190-194.

[4] Hu, W.X. (2011) The Study of the Planning and Designing about Tourist Attraction Setting Coordinated with Tourist Attraction from the Angle of Landscape Ecology-A Case Study of the Pingyao Ancient City. Human Geography, 6, 155-159.

[5] Xie, P. (2015) The Analysis of Spatial Structure Evolution for Pingyao Ancient Town. Journal of Nanjing Arts Institute Fine Arts \& Design, 1, 188-194. 
[6] Hillier, B. (1996) Space Is the Machine: A Configurational Theory of Architecture. Cambridge University Press, Cambridge.

[7] Ratti, C. (2004) Space Syntax: Some Inconsistencies. Environment and Planning B: Planning and Design, 31, 487-499. https:/doi.org/10.1068/b3019

[8] Hillier, B., Chris Stutz, C. and Huang, F. (2005) New Methods in Space Syntax. World Architecture, 11, 46-47.

[9] Liu, C.L., Yu R.L. and Duan, D.Z. (2015) The Evolution of Spatial Accessibility of Urban-rural Road Network Based on the Space Syntax in Wuhan Metropolitan Area. Scientia Geographica Sinica, 6, 698-707.

[10] Zhang Q., Xie, S.Y., Wang, X.F., Jiang, L.L., Gu, H.Y. and Liu, D.J. (2015) Evaluation on the Accessibility of the Scenic Spots in Wuhan Based on the Spatial Syntax. Economic Geography, 8, 200-208.

[11] Ye, K. (2013) The Study on Fenghuang Ancient Town Street Spaces by Space Syntax. M.S. Thesis, Huazhong Agricultural University, Wuhan.

[12] Zhang, X. and Che, Z.Y. (2012) Research on Tourism Villages' Spatial form Transform Based on Space Syntax: Taking Shuhe Ancient Town of Lijiang as an Example. Hua Zhong Architecture, 09, 105-109.

[13] Bai, Y.J. (2009) Analysis of the Street Space for Rongxiang by Space Syntax. M.S. Thesis, Jiangnan University, Wuxi.

[14] Zheng, B.H. and Zhang, B.Z. (2010) The Analysis of Historical and Cultural Areas based on Space Syntax-Taking Xiaoximen Historical and Cultural Area in Changsha as an Example. Journal of Changsha Railway University (Social Science), 2, 47-49.

[15] Dalton, B.C. (2005) Space Syntax and Spatial Cognition. World Architecture, 11, 41-45.

[16] Duan, J. and Hillier, B. (2007) Urban Space 3: Space Syntax and Urban Planning. Southeast University Press, Nanjing.

Submit or recommend next manuscript to SCIRP and we will provide best service for you:

Accepting pre-submission inquiries through Email, Facebook, LinkedIn, Twitter, etc. A wide selection of journals (inclusive of 9 subjects, more than 200 journals)

Providing 24-hour high-quality service

User-friendly online submission system

Fair and swift peer-review system

Efficient typesetting and proofreading procedure

Display of the result of downloads and visits, as well as the number of cited articles

Maximum dissemination of your research work

Submit your manuscript at: http://papersubmission.scirp.org/

Or contact jdaip@scirp.org 